\title{
Structural and Optical Properties of Fluorine Doped Tin Oxide Thin Film Deposited by Home Built Spray Pyrolysis Unit
}

\author{
Maha Prasad Koirala and Leela Pradhan Joshi * \\ Department of Physics, Amrit Science Campus, Trubhuvan University, Kathmandu, Nepal \\ *Corresponding author: leela.pradhan@gmail.com
}

\begin{abstract}
Fluorine doped Tin Oxide (FTO) thin films were deposited on glass substrates by home built spray pyrolysis setup at $(400 \pm 5)^{\circ} \mathrm{C}$. The method was found to be very economic and functional. The deposited FTO films were highly transparent and had low resistivity. The structural investigation of as-prepared films was performed using X-ray diffraction. Our results showed that a deposited FTO film was of polycrystalline nature with preferential orientation along (211) planes. The direct band gap value was found to be $3.25 \mathrm{eV}$ for $10 \%$ FTO film. The sheet resistance of this film was measured to be $68 \Omega$ / square. The effect of fluorine doping concentration on its band gap was also studied in this report.
\end{abstract}

Key Words: Spray Pyrolysis, FTO Film, Structural Property, Transmittance, Band Gap

\section{INTRODUCTION}

Transparent conducting oxide (TCO) thin films of Fluorine doped Tin Oxide (FTO) are finding wide ranges of optoelectronic device applicationsbecause of theirspecific electrical, structural and optical properties [1-2]. FTO generally exists as ann-type and wide band gap semiconductor with high transmittance in the visible region [2]. FTO has been recognized as a very promising material for a number of optoelectronic applications because of its stable nature at atmospheric conditions, mechanical hardness, chemical inertness, and high temperature durability. It has excellent electrical conductivity, greater mobility and good mechanical stability [1-3]. Due to these distinctive characteristics, it is used in solar cells as transparent and protective electrodes and in flat plate collectors as spectral selective windows for light to pass through to the active material where carrier generation occurs as an ohmic contact for carrier transport out of the photovoltaic [2,3]. It is also used in gas detecting sensors, photo thermal converters, and for providing thermal insulation for houses [1-4]. Another advantage of FTO is that it iseasy to fabricate using low cost materials. The structure, surface morphology and electrical and optical properties of the FTO films strongly depend on the method of preparation and growth parameters. Thin films of FTO can be prepared by several deposition techniques such as dip coating[5], inkjet printing [6], magnetron sputtering [7], spray pyrolysis, etc [ 8-11]. We have prepared thin films of FTO by using a homemade spray pyrolysis setup.

\section{EXPERIMENTAL}

Thin films of FTO were deposited on glass substrates by using a homemade spray pyrolysis setup. At first, a precursor solution was prepared by dissolving $10 \mathrm{~g}$ of stannous chloride in $25 \mathrm{ml}$ of distilled wateralong with a few drops of concentrated hydrochloric acid) with continuous stirring for 30 mins at $(90 \pm 5)^{\circ} \mathrm{C}$. For fluorine doping, $1 \mathrm{~g}$ of ammonium fluoride $\left(\mathrm{NH}_{4} \mathrm{~F}\right)$ was dissolved in $25 \mathrm{ml}$ of distilled water with continuous stirring for 10-15 min at (30 $\pm 5)^{\circ} \mathrm{C}$ and then mixed with the stannous chloride precursor [10]. Finally, the mixture was stirred for an hour at room temperature and allowed to rest for $24 \mathrm{hrs}$ to age it.

Before deposition of the film on the glass substrate, microscopic glass slides were ultrasonically cleaned by detergent thoroughly at first, then with acetone or ethanol to remove organic impurities, and, lastly, dried inside the hot oven. The above prepared solution was sprayed via the nozzle connected to the nebulizer. The distance between the nozzle and glass substrate was fixed at about $15 \mathrm{~cm}$. Before spraying the precursor solution, the glass substrate was heated to (400 $\pm 5)^{\circ} \mathrm{C}$. The temperature of the substratewas controlled by a temperature controller attached to a heater. The spray rate ( $\mathrm{vol} / \mathrm{min}$ ) and deposition time were controlled using apersonal computer. These sprayed samples were further annealed in air for $30 \mathrm{~min}$ at the same temperatureof deposition , $(400 \pm 5)$ ${ }^{\circ} \mathrm{C}$. They were subsequently cooled to room temperature. The structural and optical properties of as-deposited thin films of FTO were investigated by using X-ray diffraction and Ocean Optics, USB 2000, UV-Vis spectrophotometer [4]. 


\section{RESULTS AND DISCUSSION}

\subsection{Structural Properties}

The structural properties of as-prepared Fluorine doped Tin Oxide (FTO) thin films were studied using an X-ray diffraction (XRD) technique. The XRD experiment was done over the range of $20^{\circ}-80^{\circ}$ at the Nepal Academy of Science and Technology (NAST), Khumaltar, Nepal. Figure 1 shows the X-ray diffraction pattern of $10 \%$ FTO film. This figure clearly shows the major peaks at $2 \mathrm{q}=28.3661^{\circ}$, $35.6771^{\circ}$, 53.4952 ${ }^{\circ}$, and $56.1869^{\circ}$ which corresponding to orientation along (110), (200), (211), and (220) planes respectively. The (hkl) indexing was done with reference to JCPDS card no. 41-1445[4]. The table 1 below shows the observed and standard d-spacings and corresponding (hkl) values. Crystallite size of as-prepared FTO was also calculated using Debye Sherrer's formula $D=\frac{0.9 \lambda}{\beta \cos \theta}$ where $\lambda$, wavelength of $\mathrm{x}$-ray used, $\beta$, the width of peak measured at full width half maximum (FWHM) measured in radian and $\theta$, the bragg's angle. The average value of $\mathrm{D}$ was found to be about $12 \mathrm{~nm}[12]$.

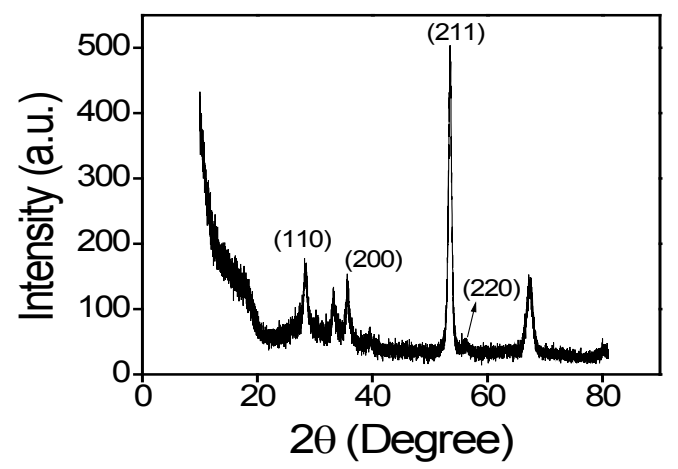

Figure 1: X-ray diffraction pattern of FTO thin film deposited on glass at $(400 \pm 5)^{\circ} \mathrm{C}$ by spray pyrolysis method

Table 2: $2 \theta$ value, (hkl), calculated and standard d-spacing values and crystallite size of $10 \%$ FTO film

\begin{tabular}{|c|l|l|l|l|l|}
\hline $\begin{array}{c}\text { S. } \\
\text { N. }\end{array}$ & \multicolumn{1}{|c|}{$\begin{array}{c}\text { (Degree) } \\
\text { d-spacing } \\
(\AA)\end{array}$} & $\begin{array}{c}\text { Calculated } \\
\text { JCPDS } \\
\text { from } \\
(\AA)\end{array}$ & $($ hkl $)$ & $\begin{array}{c}\text { Grain } \\
\text { size in } \\
(\AA)\end{array}$ \\
\hline 1 & 28.3661 & 3.1425 & 3.347 & $(110)$ & 113.7234 \\
\hline 2. & 35.6771 & 2.5135 & 2.369 & $(200)$ & 148.3530 \\
\hline 3. & 53.4952 & 1.7108 & 1.764 & $(211)$ & 133.4901 \\
\hline 4. & 56.1869 & 1.6351 & 1.675 & $(220)$ & 108.9224 \\
\hline
\end{tabular}

\subsection{Optical Measurements}

Figure $2 \mathrm{a}$ and figure $3 \mathrm{a}$ show the transmittance versus wavelength scanned in the range of $350-900 \mathrm{~nm}$ of $10 \%$ and $8 \%$ FTO thin films respectively. These spectra were captured by an Ocean Optics,UV-Visible USB 2000 spectrophotometer, Singapore. The maximum transmittance was found to be $78 \%$ at $625 \mathrm{~nm}$ for $10 \%$ FTO whereas it was $72 \%$ at $660 \mathrm{~nm}$ for $8 \%$ FTO. Corresponding $(\alpha h v)^{2}$ versus $\mathrm{h} v(\mathrm{eV})$ graphs were shown in figure $2 \mathrm{~b}$ for $10 \%$ FTO film and figure $3 \mathrm{~b}$ for $8 \%$ FTO film respectively. The band gaps of FTO films were calculated by extrapolating the linear portion of $(\alpha h v)^{2}$ into the $h v$ axis $[12,13]$. The measurements show that the direct band gap of about $3.25 \mathrm{eV}$ and $3.24 \mathrm{eV}$ for $10 \%$ and $8 \%$ FTO films. Hence our results showed that as the fluorine concentration increased, the transmittance increased by about $6 \%$ but there was no significant change in the band gap.
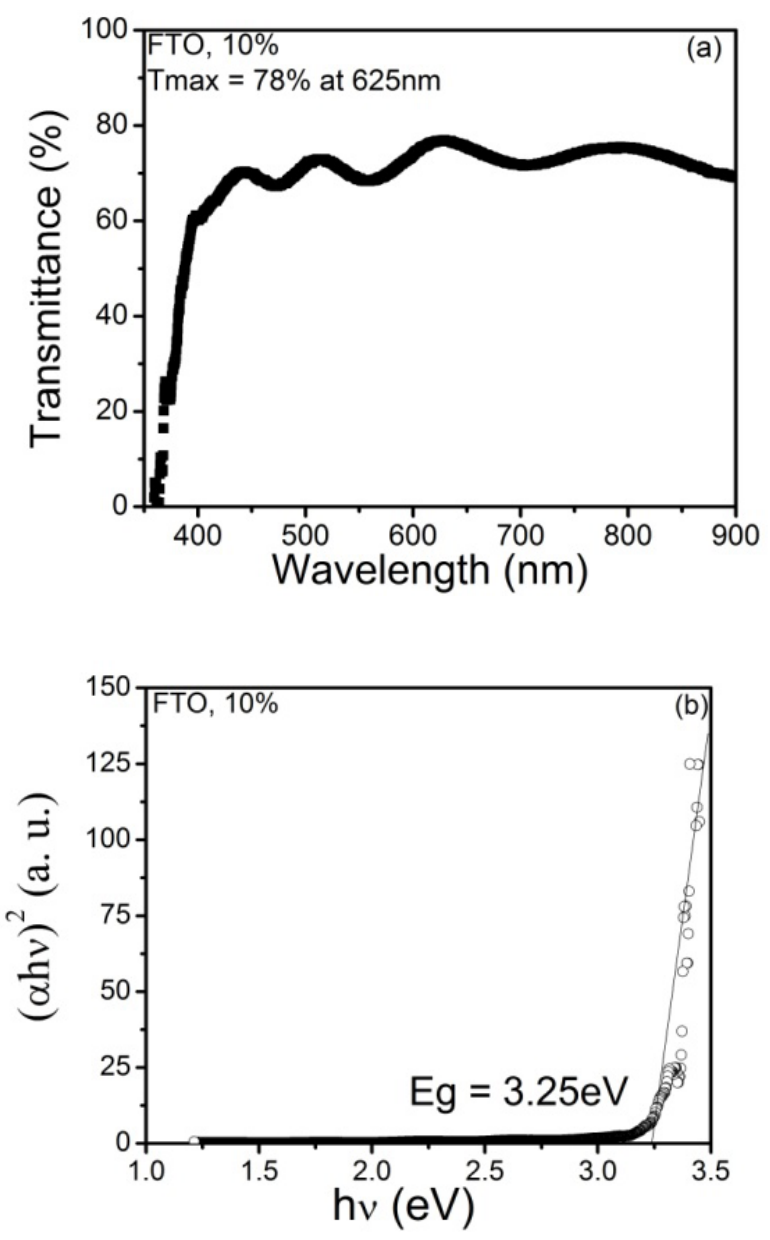

Figure 2: (a) The transmittance versus wavelength (b) corresponding to $(\alpha h v)^{2}$ versus hv of $10 \%$ FTO film 

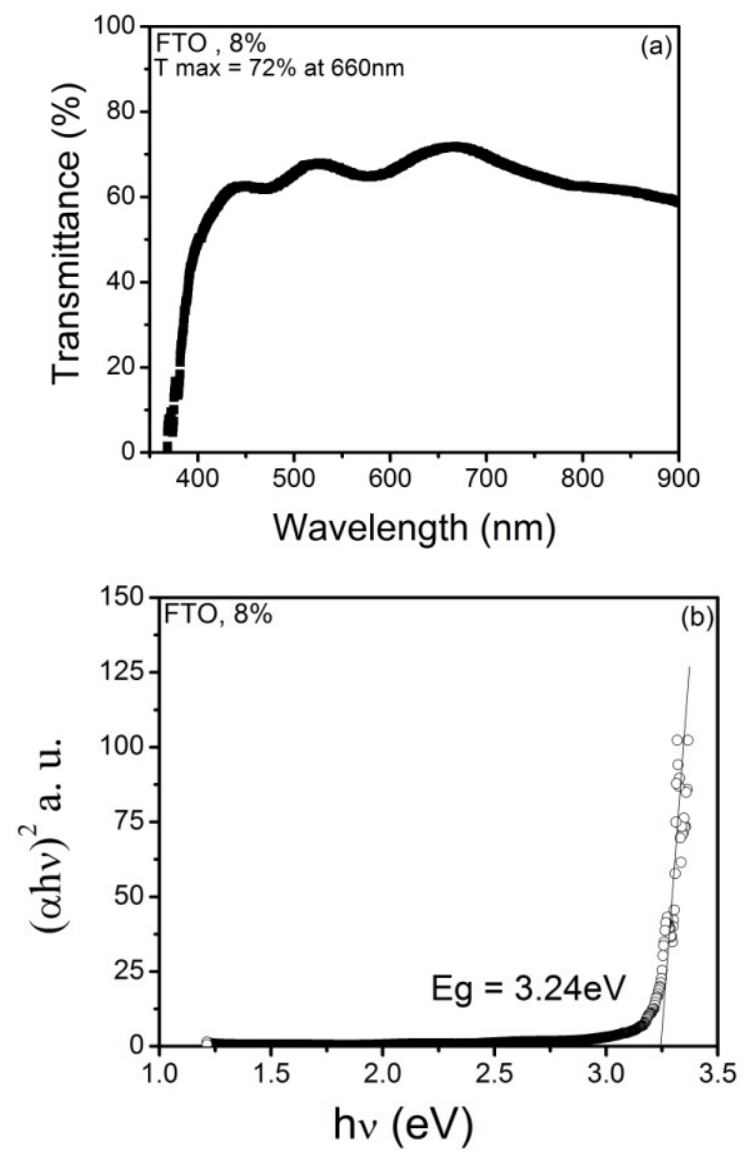

Figure 3: (a) The transmittance versus wavelength

(b) corresponding to $(\alpha h v)^{2}$ versus $h v$ of $8 \%$ FTO film

\subsection{Electrical measurement}

The sheet resistances of above prepared FTO thin films were studied using the four point probe technique $[13,14]$.

We observed that as the low volume of solution was sprayed into the glass substrate, the sheet resistance wasfound to be high due to only athin layer of FTO deposited. Our results showed the lowest sheet resistance of $68 \mathrm{ohm} / \mathrm{square}$ for $10 \%$ FTO film and $55 \mathrm{ohm} / \mathrm{square}$ for $8 \%$ doped film.

\section{CONCLUSIONS}

Semiconducting thin films of Fluorine doped Tin Oxide (FTO) were successfully deposited on glass substrates using a homemade spray pyrolysis setup at $(400 \pm 5){ }^{\circ} \mathrm{C}$. The method was found to be economic and suitable for research and development. The transmittance of $10 \%$ FTO film was found to be of $78 \%$ at $625 \mathrm{~nm}$ and sheet resistance $68 \mathrm{ohm} / \mathrm{square}$. The direct band gap was found to be of $3.25 \mathrm{eV}$ for $10 \%$ FTO film. The X-ray analysis confirmed the polycrystalline nature of FTO film with preferential orientation along (211) planes.

\section{ACKNOWLEDGMENT}

We would like to thank the Amrit Campus family for providing required facilities including utilities and Prof. S. P. Shrestha, Patan Multiple Campus, Patan Dhokha for helping us to complete optical measurements using the USB 2000 spectrophotmeter.

\section{REFERENCES}

[1] E. Elangovan, and K. Ramamurthi, Journal of Optoelectronics and Advanced Materials 5, 45 (2003).

[2] H. Liu, V. Avrutin, N. Izyumskaya, U. Ozgur, and H. Morkoc, Superlattices and Microstructures, 48, 458 (2010).

[3] J. -C. Manifacier, L. Szepessy, J. F. Bresse, and M. Perotin, Material Research Bulletin, 14, 163 (1979).

[4] C.-W. Cho, J.-H. Lee, D.-H Riu, and C.-Y. Kim, Japanese Journal of Applied Physics, 51, 045001 (2012).

[5]A. N. Benerjee, S. Kundoo, P. Saha, and K. Chattopadhya, Journal of Sol-Gel Science and Technology, 28, 105 (2003).

[6] W. Z. Samad, M. M. Salleh, A. Shafiee, A., and M. A. Yarmo, Sains Malaysiana 40(3), 251 (2011).

[7] Z. Y. Banyamin, P. J. Kelly, G. West, and J. Boardman, Coatings 4, 732 (2014).

[8] E. Shanthi, A. Banerjee, and K. L. Chopra, Thin Solid Films, 88, 93 ( 1982).

[9] S. Shanthi, H. Anuratha, C. Subramanian, and P. Ramasamy, Journal of Crystal Growth, 194, 369 (1998).

[10] D. Tatar, G. Turgut, and B. Duzgun, Romanian Journal of Physics, 58, 43 ( 2013).

[11] Ikhmayies, S.J., Ahamad-Bitar, R., Material Science in Semicondtor Process, 12, 122 (2009).

[12] V. Bilgin, I. Akyuz, E. Ketenci, S. Kose, and F. Atay, Applied Surface Science, 256 , 6586 (2010).

[13] D. Tatar, and B. Duzgun, Pramana Journal of Physics, 79(1), 137 (2012).

[14 ] L. J. Van der pauw, Philips Research Reports, 13, 1 (1958). 